Article

\title{
A multi-domain group-based intervention to promote physical activity, healthy nutrition, and psychological wellbeing in frail older people: AMICOPE development study
}

\author{
Sergi Blancafort Alias ${ }^{*}$ * (SBA), César Cuevas-Lara ${ }^{2}$ (CC-L), Nicolás Martínez-Velilla² (NM-V), Fabricio Zambom- \\ Ferraresi $^{2}$ (FZ-F), Maria Eugenia Soto ${ }^{3}$ (MES), Neda Tavassoli ${ }^{3}$ (NT), Céline Mathieu ${ }^{3}$ (CM), Eva Heras Muxella ${ }^{4}$ \\ (EHM), Pablo Garibaldii (PG), Maria Anglada ${ }^{4}$ (MA), Jordi Amblàs ${ }^{5}{ }^{6}$ (JA), Sebastià Santaeugènia ${ }^{5}{ }^{6}(\mathrm{SS})$, Joan \\ Carles Contel $^{5}{ }^{6}$ (JCC), Àlex Domingo Riau ${ }^{1}$ (ADR) and Antoni Salvà Casanovas ${ }^{1}$ (ASC)
}

1 Fundació Salut i Envelliment (Foundation on Health and Ageing)- UAB, Universitat Autònoma de Barcelona, Barcelona, Spain; sergi.blancafort@uab.cat; alexandre.domingo@uab.cat; antoni.salva@uab.cat

2 Navarrabiomed, Geriatrics Department, Hospital Complex of Navarra (CHN) - Public University of Navarra (UPNA), Navarra Health Research Institute (IdisNa), Pamplona, Navarra, Spain; nicolas.martinez.velilla@navarra.es; fabricio.zambom.ferraresi@navarra.es; cesar.cuevas.lara@navarra.es

3 Equipe Régional Vieillissement et Prévention de la Dépendance, Gérontopôle, Centre Hospitalier Universitaire de Toulouse, Toulouse, France; soto-martin.me@chu-toulouse.fr; tavassoli.n@chu-toulouse.fr; mathieu.ce@toulouse.fr

4 Ageing and Health Department in the Andorran Healthcare System, Servei Andorrà d'Atenció Sanitaria, Andorra; eheras@saas.ad; pagaribaldi@saas.ad; manglada@saas.ad

5 Chronic Care Program, Ministry of Health, Generalitat de Catalunya, Catalonia, Spain; jamblas_ext@gencat.cat; sebastia.santaeugenia@gencat.cat; jccontel@gencat.cat

6 Central Catalonia Chronicity Research Group (C3RG), Centre for Health and Social Care Research (CESS), University of Vic/Central University of Catalonia (UVIC-UCC). Vic, Barcelona, Spain

* Correspondence: sergi.blancafort@uab.cat

\begin{abstract}
The World Health Organization has developed the Integrated Care of Older People (ICOPE) strategy, a program based on the measurement of intrinsic capacity (IC) as "the composite of all physical and mental attributes on which an individual can draw". Multicomponent interventions appear to be the more effective approach to enhance IC and to prevent frailty and dependence, being adapted physical activity is the preventive intervention that has shown more evidence in the treatment of frailty and risk of falls. The present study aims to describe the development of a multi-domain group-based intervention addressed to frail older people living in the community aimed to improve and/or maintain intrinsic capacity by means of promoting physical activity, healthy nutrition, and psychological wellbeing in frail older people. We used the GUIDED checklist to describe the development process of AMICOPE (Aptitude Multi-domain group-based intervention to improve and/or maintain IC in frail Older PEople). The intervention was built upon the ICOPE framework and it is described with Template for Intervention Description and Replication (TIDieR) guidelines and it includes dietary advice, cognitive stimulation strategies, medication review, goal setting, and activities to strengthen social support and manage depressive symptoms, as well as strength, balance and flexibility exercise using the Vivifrail program. The study represents the first stage of the UK Medical Research Council framework for developing and evaluating a complex intervention. The next step should be carrying out a feasibility study for the AMICOPE intervention, and in a later stage, assessing the effectiveness in a randomized controlled trial.
\end{abstract}

Keywords: Intrinsic capacity; integrated care; multi-domain intervention; physical exercise; nutrition; psychological wellbeing; frailty; complex intervention; intervention development study

\section{Introduction}


Although the incidence of severe disability has decreased in recent decades, especially in developed countries, the proportion of people with mild or moderate disability has increased [1]. In addition, more than half of the elderly patients are affected simultaneously by multiple diseases and take simultaneously four or more prescribed medicines, increasing the risk of drug-related interaction causing functional decline and side effects [2,3]. However, health classifications and therapeutic recommendations with a single-disease approach have traditionally undervalued several health conditions such as the so-called geriatric syndromes that negatively affect health and quality of life [4], amongst which frailty stands out. Despite the difficulty of reaching an agreement for a common definition of frailty, it could be described as an ageing-related state characterized by major vulnerability for negative health outcomes and increased risk of disability, dependence, falls, long-term care needs and mortality [5,6] and being frail older people with the lowest income and educational level the most vulnerable [7].

This situation raises the need for a paradigm change in the approach to the health care of the older people [8]. After the publication of the model of active ageing [9], the World Health Organization (WHO) recently has supported the creation of a new model of care focused on the preservation of functional capacity, which has shown to be a good predictor of morbidity and mortality in older people [10]. Within this framework, the WHO has developed the Integrated Care of Older People (ICOPE) strategy, a program based on the measurement of intrinsic capacity (IC) as "the composite of all physical and mental attributes on which an individual can draw" [11]. The ICOPE strategy establishes the subsequent five steps: screening for declines in domains of IC (step 1), assessment of environmental, health and social needs (step 2), development of a customized care process advised by a person-centered appraisal (step 3), patient referral and supervision of care process (step 4) and getting involved in communities and reinforce caregivers (step 5). Step 3 implies an integrated plan to carry out interventions dealing with declines in several domains of intrinsic capacity, which should be contemplated and put together. Moreover, self-management and prioritization of health objectives in accordance with patients' needs, expectations and preferences should be a transverse feature of such multidomain interventions [12]. As for the step 5, it emphasizes the importance for older people to receive information about available community-based resources, and the need for health assets in the neighborhood to be involved in supporting care, according to recent social prescribing approaches [13].

The identification of functions and capacities contributing to the definition of IC is structured into five domains that correspond to cognition, mobility, vitality (which addresses poor nutrition), psychological (which address depressive symptomatology) and sensorial domain (vision and hearing) [14]. These domains and health conditions associated with IC interact at several levels, and many of their contributing factors can be modified. However, strict lockdowns adopted by governments in the context of the COVID-19 pandemic has had a negative impact on several domains of IC [15]. Mobility is a critical issue for healthy ageing and preventing dependence on care. In fact, structured and adapted physical activity is the preventive intervention that has shown more evidence in the treatment of frailty and risk of falls. Physical exercise benefits are associated with a decrease in the risk of mortality, chronic disease, institutionalization, and cognitive and functional impairment. Particularly, programs including strength, balance, flexibility, and aerobic exercises have reported the greatest outcomes [16-31]. Researchers also has reported the effect of self-management and behaviour change strategies that may help older people to increase adherence and adoption of healthier lifestyles [32-34]. As for the vitality domain, most programs addressing frail older people also include a nutritional intervention, as it has been proven to increase the gains of physical exercise [35-38]. The ICOPE strategy considers offering dietary advice and highlight the importance to outcome barriers to people's nutritional health, sociability dining -particularly for those living alone or socially isolated-, arrange assistance with preparation and provision of food, identify specific seasonal and proximity foods, and 
advise on the adequate amount of these foods [39]. Concerning the psychological domain, literature shows how several structured approaches and therapies, such as Cognitive Behavioural Therapy (CBT), problem-solving, behavioural activation and life review, are susceptible to be modified into brief interventions to address depressive symptoms [40]. Regarding this latter, another critical issue to be considered is strengthening social support and staying socially connected to tackle loneliness and social isolation [41] as well as providing a list of local community services available to older people and encourage their use to increase their participation in identifying potential barriers to community engagement [13].

Thus, there is a need to develop and assess community-based interventions to enhance intrinsic capacity and prevent frailty and dependence. Among them, and based on available evidence, multi-component interventions appear to be more effective [11]. The purpose of this article is to describe the development of a multi-domain group-based intervention addressed to frail older people living in the community aimed to improve and/or maintain intrinsic capacity by means of promoting physical activity, healthy nutrition, and psychological wellbeing in frail older people.

\section{Materials and Methods}

In this study we use the "Guidance for reporting intervention development studies in health research" (GUIDED) checklist [42] to detail the development process of AMICOPE intervention. The text below describes the process of intervention development in relation to the 14 items of the GUIDED checklist. The intervention was developed in the context of two different projects. On the one hand, the APTITUDE project [43], and on the other, the model for the prevention of disability and the promotion of personal autonomy in Catalonia [44]. APTITUDE is a European project funded by POCTEFA 2014-2020, which is the acronym of the INTERREG V-A Spain-France-Andorra Program. The APTITUDE project involves 11 different territories from Occitania, Andorra, Navarra, and Catalonia in the cross-border area of the Pyrenees. The general objective of APTITUDE is to prevent the dependency on older people by creating a network to promote care, training, research, and innovation in the areas of public health and gerontology. The network was structured with local coordination referents $(n=10-15)$ and operational teams $(n=50-100)$ in each territory. The model for the prevention of disability and the promotion of personal autonomy is a joint initiative of the Department of Health and the Department of Labor, Social Affairs and Families of the Catalan Government. This project has already started in five pilot territories and should be progressively implemented over the next years throughout Catalonia.

The target population of AMICOPE corresponds to frail older people living in the community with losses in mobility, nutritional and/or psychological domains of intrinsic capacity, and without cognitive decline, visual impairment or hearing loss. Our appraisal was theory and evidence-based, as well as coherent with the framework of the Medical Research Council (MRC) for the development and evaluation of complex interventions [45]. This framework is appropriate to be applied for those interventions including a number of components interacting one with each other, several recipients and outcomes, different skills needed by the facilitators and certain level of tailoring. During the intervention development process, decisions were taken in accordance with evidence from resembling interventions delivered to frail older people, and results from our previous studies. We also integrated the recommendations of a working group, the appropriateness of different frameworks used in implementation research, and evidence shown by few strategies which seemed to be effective. Figure 1 illustrates how evidence from different sources enlightened the intervention development process of AMICOPE intervention. 


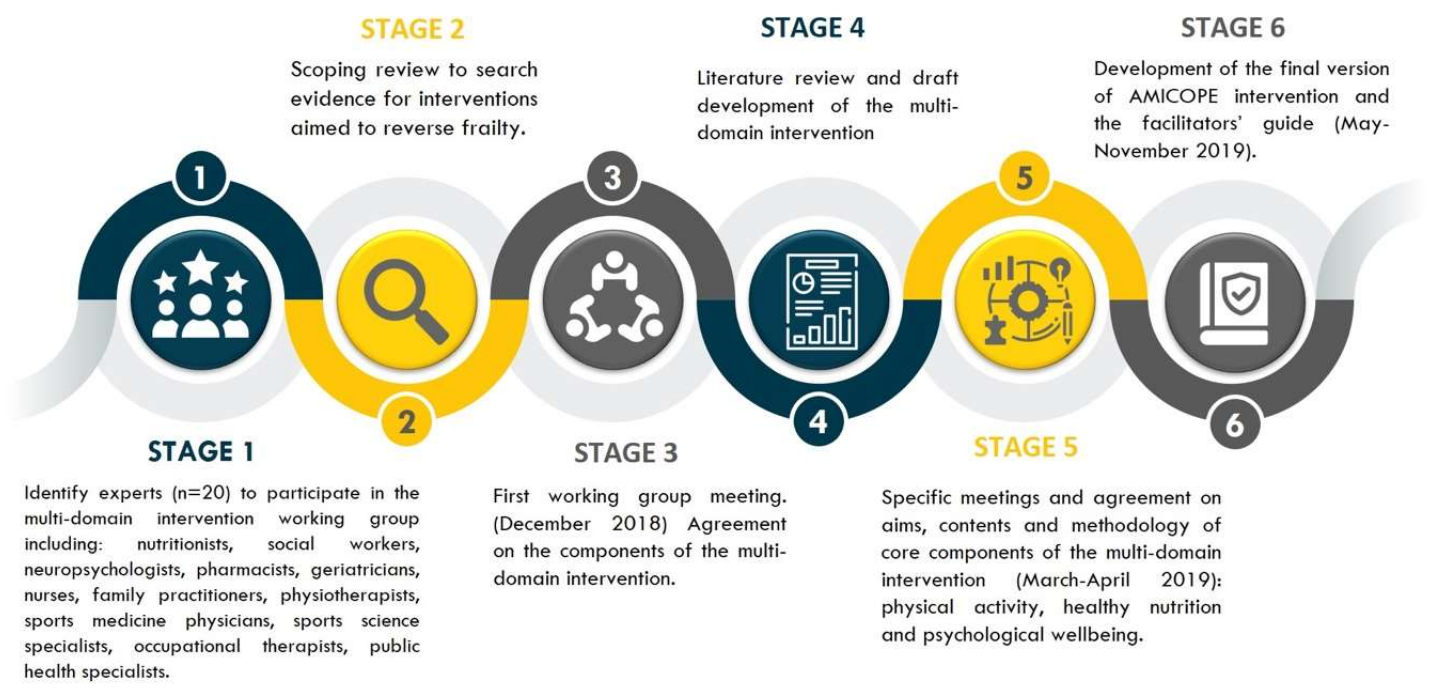

Figure 1. Development process of AMICOPE intervention.

The theoretical rationale driving the design and the development of this multidomain intervention was the ICOPE program of the WHO [11]. Rather than creating an entirely new intervention, AMICOPE was developed by incorporating components adopted from already existing interventions that have shown evidence in increasing functional capacity and improving mental health in older people. Hence, the Vivifrail program [46] was used for the domain of physical activity, and some methodologies used in the "Feeling Well" program [47] (e.g. mapping party, photo-ellicitation, goal setting) were applied for the domain of psychological wellbeing and to promote behaviour change. An intervention guide for the facilitators set up a frame to lead group activities adhering to general basic rules detailed in a decalogue and a common structure whilst taking into account participants' preferences, needs and expectations.

A working group including members appointed by the Department of Health and the Department of Labor, Social Affairs and Families, and members of the APTITUDE network, reviewed the general scope of the intervention in a first stage of the process development and contributed to defining some critical aspects of each component. This working group included health and social care professionals, members of local administrations, community representatives and entrepreneurs of the silver economy, among other stakeholders. Evolving versions of the intervention were presented during the development process to integrate stakeholder contributions. Due to the iterative and complex nature of the intervention development process, some changes affected the scope of the intervention. Hence, and even though it was beyond the intervention's initial aims, specific contents about cognitive stimulation and medication review were suggested by the working group and finally incorporated as part of the intervention that was defined at the end of the development process. The intervention also considered different types of physical activity according to the frailty level of participants. At the end of the development process, some uncertainties remained mainly related to the implementation of the intervention in isolated, sparsely, and low-density rural areas of the Pyrenees, and the impact of the COVID-19 pandemic in the realization of group-based activities with older people. The current publication is open access and materials of AMICOPE multidomain intervention are available on demand.

\section{Results}

The result of the study is a group-based multi-domain complex intervention described according to the TIDieR (Template for intervention description and replication) guidelines [48]. The intervention is called "AMICOPE" (Aptitude Multi-domain 
intervention to promote Intrinsic Capacity in Older PEople), and it is aimed at promoting physical activity, healthy nutrition and psychological wellbeing in frail older people living in the community. The guiding principle of our work was the ICOPE strategy [11] and the conceptual framework of the intervention is described in fig. 2.

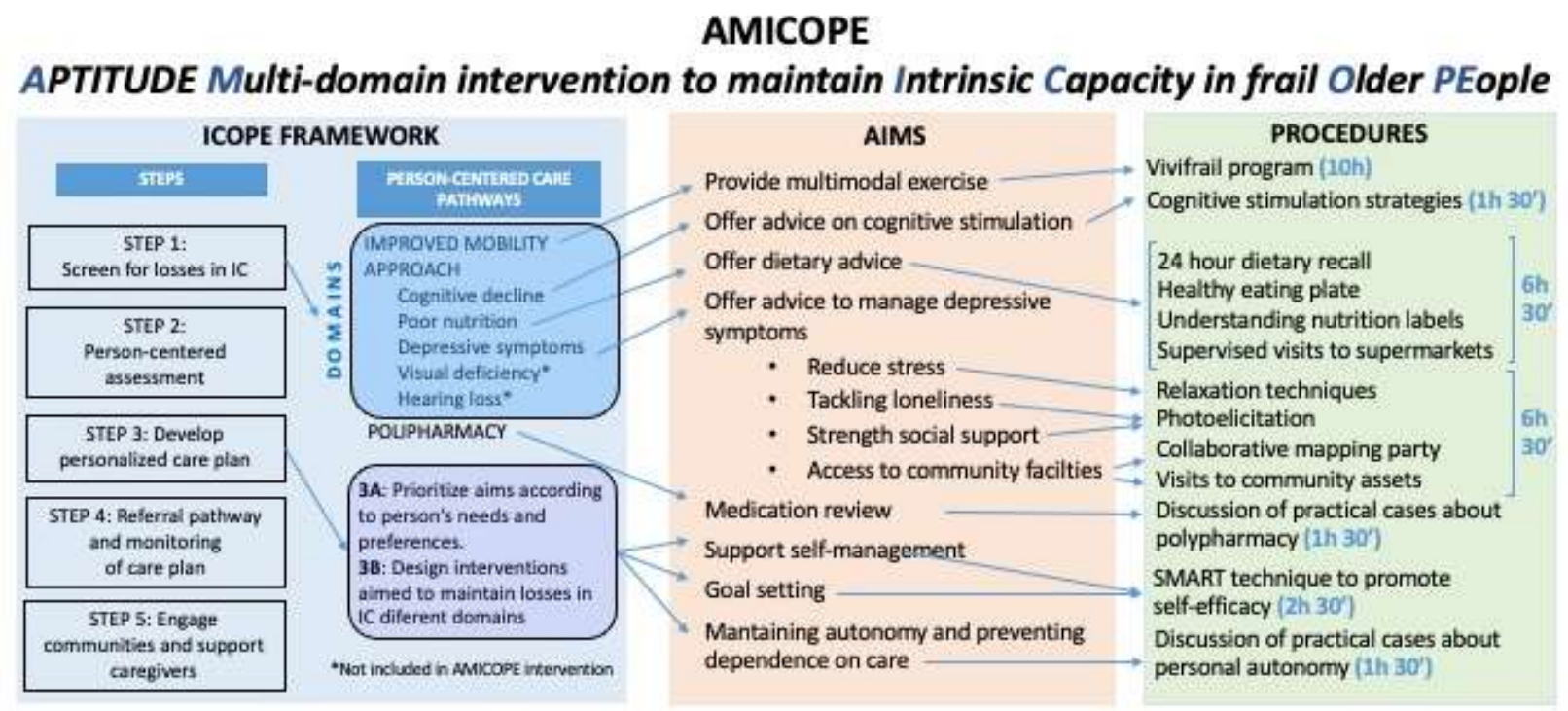

Figure 2. Conceptual framework of the AMICOPE multi-domain intervention.

The materials to be used in the intervention include a detailed guide for the facilitators, Vivifrail physical exercise program resources (passports, App and videos), and working sheets, maps, photographs, and audio files to perform some other activities. The intervention procedures for physical activity were based on strength, balance, flexibility and aerobic exercises. Several group dynamics were designed to promote social support and exchange of personal experiences among participants, as well as the acquisition of self-management skills. Goal setting will be used to promote behavioural changes in the daily life of participants that are meaningful for them and that positively affect their healthy nutrition and psychological wellbeing. A pair of health and social care professionals with different background (nurse, physiotherapist, occupational therapist, nutritionist, psychologist, physical activity trainer, etc.) will be previously trained as group facilitators by the research team, during a 30-hour training program based on how to apply the intervention guide.

The intervention consists of 12 face-to-face sessions and facilitated in groups of 8 to12 frail older people. Sessions are held weekly for 2.5 hours during three months. Each session includes one hour of physical exercise using the Vivifrail program, and 1.5 hours dedicated to any other intervention components. The intervention will be delivered in community facilities such as senior leisure centers, civic centers, or primary care centers, and in different locations of the surroundings. Particularly, 10 of the 12 sessions will take place in a space large enough to do physical activity. For one session the whole group will move to a food store or supermarket to learn about nutritional facts. The remaining session will be devoted to visit another senior center with the purpose to know about programs and activities addressed to the community.

The physical activity domain of AMICOPE includes individual prescription passports for participants tailored to their individual functional capacity, which will be assessed by the Short Physical Performance Battery (SPPB), a walking speed test, and the risk of falls. Nevertheless, other activities are intended to facilitate adherence to the intervention, enhance social cohesion and change lifestyles. Hence, participants bring to the group personal objects to introduce themselves and share SMART goals in accordance 
with their own preferences to increase self-efficacy. Finally, outings are chosen and agreed after a group mapping activity of local community assets, and this allows each intervention to be -beyond individual interests and preferences- slightly adapted to a specific context.

The intervention was planned to be piloted in Catalunya and ten health and social professionals (six nurses, two physiotherapists and two physical activity trainers) were trained during November and December of 2019. A pilot of AMICOPE intervention addressed to a group of 12 frail older people started in Tortosa (Baix Ebre/Spain) in the beginning of February 2020 but had to be dramatically cancelled after six sessions due to the outbreak of the COVID-19 pandemic in Spain. A feasibility study will be conducted in the territories of the APTITUDE project to pilot the intervention, to incorporate any modifications that may improve the design, procedures, or implementation. For that purpose, one or two health or social care professionals will monitor the intervention to fill an observation log that includes several quantitative and qualitative indicators of implementation such as fidelity and adherence.

\section{Discussion}

In this study we use the GUIDED checklist to describe the intervention development process for the AMICOPE group-based multi-domain intervention. We rationalize the process by detailing: the context, the aim, the recipients, the theory and evidence-base, the utilization of previous experiences, the guiding principles, the participation of stakeholders, the changes made throughout the process, and remaining uncertainties. The intervention itself is described using the TIDieR checklist and reporting of the intervention development process draws on frameworks such as the WHO Integrated Care of Older People and the UK Medical Research Council framework to develop and evaluate complex interventions.

The AMICOPE intervention is addressed to frail older people living in the community and aims to improve and/or maintain IC by promoting physical activity, healthy nutrition, and psychological well-being in frail older people. A multimodal exercise program tailored to individual capacities and needs has been suggested as the most important approach to improve or maintain locomotor capacity [11,16-31]. The significant contribution of nutrition to frailty has also been underlined by some authors $[35,37]$. However, other researchers have suggested that nutritional interventions delivered alone may not be effective for the management of frailty on older people [49]. As for the psychological domain, previous studies showed that group-based interventions addressing loneliness and social isolation could help to reduce depressive symptoms $[41,50]$. During the development process, specific and brief contents about cognitive stimulation and medication review were finally incorporated as part of the intervention, though it was beyond the initial aims of the intervention. This decision was taken on the basis that preventive cognitive training has benefits for older people, as reported by researchers [51]. Medication review can reduce polypharmacy by eliminating unnecessary, ineffective and medications with a duplicative effect [52]. Nevertheless, scientific literature has evidenced that most factors related to losses in intrinsic capacity share the same underpinning physiological and behavioural causes [11]. Hence, interventions have benefits across different domains of IC. Physical exercise prevents loss of mobility but also has indirect preventive effects against depression and cognitive decline [16]. Nutrition reinforces the effects of exercise [35-37]. Loneliness increases the risk of malnutrition [53]. Finally, we included goal setting as a cross-sectional element in our intervention, which has been considered by some authors as an effective behavior change technique as well as a fundamental component of successful interventions [54], including those promoting dietary and physical activity [55] and particularly when integrated in complex interventions addressed to older people [56]. 


\section{Strenghts and limitations}

To our knowledge, AMICOPE is the first group-based complex intervention aimed to improve some components of intrinsic capacity in older people, that it is built upon the ICOPE framework. Although the intervention proposed in this study covers most of the IC components, we were not able to incorporate any components addressing visual deficiency and hearing loss, both related to the sensorial domain.

The use of the GUIDED checklist provides a detailed information about the intervention development process and allow researchers to understand important aspects when developing multi-domain intervention addressing frailty and/or losses in IC. We hope this will help the scale-up, replication, adaptation, or more comprehensive implementation of AMICOPE in other settings. We also think that the approach described in this study can be used as a model for future research in the development of complex interventions. Scientific literature is scarce for published intervention development studies. To date, the few examples found using the GUIDED checklist includes two PubMed peer-reviewed articles reporting interventions aimed to improve mental health help-seeking behaviours for male students [57], and tamoxifen adherence in breast cancer [58]; two preprints reporting interventions aimed to improve early diagnosis of cancer in primary care [59] and targeting antipsychotic prescribing to nursing home residents with dementia [60]; and one doctoral thesis reporting an arts-based intervention for patients with kidney disease [61].

Another significant limitation is that the initial pilot of AMICOPE was cancelled after having completed only half of the intervention, due to the outbreak of the COVID-19 pandemic. This paper reports an intervention development study as the first stage of the UK Medical Research Council framework for developing and evaluating a complex intervention. The next step should be carrying out a feasibility study for the AMICOPE intervention, and in a later stage, assessing the effectiveness in a randomized controlled trial.

\section{Conclusions}

This paper describes the development process of AMICOPE, a group-based multidomain complex intervention built upon the ICOPE framework and aimed to improve and/or maintain IC through the promotion of physical activity, healthy nutrition, and psychological wellbeing in frail older people. The study is reported according to the GUIDED checklist and represents the first stage of the UK Medical Research Council framework for developing and evaluating a complex intervention. The next step should be carrying out a feasibility study for the AMICOPE intervention, and in a later stage, assessing the effectiveness in a randomized controlled trial.

Author Contributions: All authors have read and agreed to the published version of the manuscript. Conceptualization, SBA, CC-L, NM-V, FZ-F, EHM, PG, MA, MES, NT, CM, JA, SS, JCC and ASC; Funding acquisition, NM-V, EHM, MES, and ASC; Methodology, SBA, CC-L, NM-V, FZF, JA, JCC and ASC; Project administration, SBA, CC-L, NM-V, EHM, JA, JCC, AD and ASC; Resources, SBA, CC-L, NM-V, FZ-F, EHM, JA, JCC, SS and ASC; Software, CC-L, NM-V, and FZ-F; Supervision, NM-V, EHM, MES, SS and ASC; Visualization, SBA and CC-L; Writing - original draft, SBA; Writing - review \& editing, SBA, CC-L, NM-V, FZ-F, MES, NT, CM, EHM, PG, MA, JA, JCC, SS, AD and ASC.

Funding: This research was funded by the program POCTEFA (European Union) in the context of the APTITUDE project, reference EFA232/16.

Acknowledgments: The authors would like to thank Anna Vila and Aina Plaza from the Department of Labor, Social Affairs and Families of the Catalan Government, as well as the members of the working group involved in the development process of AMICOPE for their contribution. NM-V received funding from "la Caixa" Foundation (ID 100010434), under agreement LCF/PR/PR15/51100006. 
Conflicts of Interest: The authors declare no conflict of interest. The funders had no role in the design of the study; in the collection, analyses, or interpretation of data; in the writing of the manuscript, or in the decision to publish the results.

\section{References}

1. Chatterji, S.; Byles, J.; Cutler, D.; Seeman, T.; Verdes, E. Health, functioning, and disability in older adults--present status and future implications. Lancet 2015, 385(9967), 563-575. https://doi.org/10.1016/S0140-6736(14)61462-8

2. Marengoni, A.; Angleman, S.; Melis, R.; Mangialasche, F.; Karp, A.; Garmen, A.; Meinow, B.; Fratiglioni, L. Aging with multimorbidity: a systematic review of the literature. Ageing Res. Rev. 2011, 10(4), 430-439. https://doi.org/10.1016/j.arr.2011.03.003

3. Arokiasamy, P.; Uttamacharya, U.; Jain, K.; Biritwum, R.B.; Yawson, A. E.; Wu, F.; Guo, Y.; Maximova, T.; Espinoza, B.M.; Rodríguez, A.S.; Afshar, S.; Pati, S.; Ice, G.; Banerjee, S.; Liebert, M. A.; Snodgrass, J. J.; Naidoo, N.; Chatterji, S.; Kowal, P. The impact of multimorbidity on adult physical and mental health in low- and middle-income countries: what does the study on global ageing and adult health (SAGE) reveal? BMC Med. 2015, 13, 178. https://doi.org/10.1186/s12916-015-0402-8

4. Inouye, S.K.; Studenski, S.; Tinetti, M.E., Kuchel, G.A. Geriatric syndromes: clinical, research, and policy implications of a core geriatric concept. J. Am. Geriatr. Soc. 2007, 55(5), 780-791. https://doi.org/10.1111/j.1532-5415.2007.01156.x

5. Fried, L.P.; Ferrucci, L.; Darer, J., Williamson, J.D.; Anderson, G. Untangling the concepts of disability, frailty, and comorbidity: implications for improved targeting and care. J. Gerontol. 2004, 59(3), 255-263. https://doi.org/10.1093/gerona/59.3.m255

6. Clegg, A.; Young, J.; Iliffe, S.; Rikkert, M.O.; Rockwood, K. Frailty in elderly people. Lancet 2013, 381(9868), 752-762. https://doi.org/10.1016/S0140-6736(12)62167-9

7. Harttgen, K.; Kowal, P.; Strulik, H.; Chatterji, S.; Vollmer, S. Patterns of frailty in older adults: comparing results from higher and lower income countries using the Survey of Health, Ageing and Retirement in Europe (SHARE) and the Study on Global AGEing and Adult Health (SAGE). PloS One 2013, 8(10), e75847. https://doi.org/10.1371/journal.pone.0075847

8. Beard, J.R.; Officer, A.; de Carvalho, I.A.; Sadana, R.; Pot, A.M.; Michel, J.P.; Lloyd-Sherlock, P.; Epping-Jordan, J.E.; Peeters, G.; Mahanani, W.R.; Thiyagarajan, J.A.; Chatterji, S. The World report on ageing and health: a policy framework for healthy ageing. Lancet 2016, 21;387(10033), 2145-2154. https://doi.org/10.1016/S0140-6736(15)00516-4

9. World Health Organization. Active Ageing: a Policy Framework. WHO: Geneva, Switzerland, 2002.

10. Stuck, A.E.; Siu, A.L.; Wieland, G.D.; Adams, J.; Rubenstein, L.Z. Comprehensive geriatric assessment: a meta-analysis of controlled trials. Lancet 1993, 342(8878), 1032-1036. https://doi.org/10.1016/0140-6736(93)92884-v

11. World Health Organization. Integrated care for older people (ICOPE): guidance for person-centered assessment and pathways in primary care. WHO: Geneva, Switzerland, 2019.

12. van Het Bolscher-Niehuis, M.J.; den Ouden, M.E.; de Vocht, H.M.; Francke, A.L. Effects of self-management support programmes on activities of daily living of older adults: A systematic review. Int. J. Nurs. Stud. 2016, 61, 230-247. https://doi.org/10.1016/j.ijnurstu.2016.06.014

13. Pescheny, J.V.; Randhawa, G.; Pappas, Y. The impact of social prescribing services on service users: a systematic review of the evidence. Eur. J. Public Health 2020, 30(4), 664-673. https://doi.org/10.1093/eurpub/ckz078

14. Cesari, M.; Araujo de Carvalho, I.; Thiyagarajan, J.A.; Cooper, C.; Martin, F.C.; Reginster, J.Y.; Vellas, B.; Beard, J.R. (2018). Evidence for the Domains Supporting the Construct of Intrinsic Capacity. J. Gerontol. 2018, 73(12), 1653-1660. https://doi.org/10.1093/gerona/gly011

15. Nestola, T.; Orlandini, L.; Beard, J.R.; Cesari, M. COVID-19 and Intrinsic Capacity. J. Nutr. Health Aging 2020, $24(7)$, 692-695. https://doi.org/10.1007/s12603-020-1397-1

16. Tarazona-Santabalbina, F.J.; Gómez-Cabrera, M.C.; Pérez-Ros, P.; Martínez-Arnau, F.M.; Cabo, H.; Tsaparas, K.; Salvador-Pascual, A.; Rodriguez-Mañas, L.; Viña, J.A Multicomponent Exercise Intervention that Reverses Frailty and Improves Cognition, Emotion, and Social Networking in the Community-Dwelling Frail Elderly: A Randomized Clinical Trial. J. Am. Med. Dir. Assoc. 2016, 17(5), 426-433. https://doi.org/10.1016/j.jamda.2016.01.019

17. Martínez-Velilla, N.; Casas-Herrero, A.; Zambom-Ferraresi, F.; Sáez de Asteasu, M.L.; Lucia, A.; Galbete, A.; García-Baztán, A.; Alonso-Renedo, J.; González-Glaría, B.; Gonzalo-Lázaro, M.; Apezteguía Iráizoz, I.; Gutiérrez-Valencia, M.; Rodríguez-Mañas, L.; Izquierdo, M. Effect of Exercise Intervention on Functional Decline in Very Elderly Patients During Acute Hospitalization: A Randomized Clinical Trial. JAMA Intern. Med. 2019, 179(1), 28-36. https://doi.org/10.1001/jamainternmed.2018.4869

18. Sáez de Asteasu, M.L.; Martínez-Velilla, N.; Zambom-Ferraresi, F.; Casas-Herrero, Á.; Cadore, E.L.; Galbete, A.; Izquierdo, M. Assessing the impact of physical exercise on cognitive function in older medical patients during acute hospitalization: Secondary analysis of a randomized trial. PLoS Med. 2019, 16(7), e1002852. https://doi.org/10.1371/journal.pmed.1002852 
19. Sáez de Asteasu, M.L.; Martínez-Velilla, N.; Zambom-Ferraresi, F.; Casas-Herrero, Á.; Cadore, E.L.; Ramirez-Velez, R.; Izquierdo, M. Inter-individual variability in response to exercise intervention or usual care in hospitalized older adults. J. Cachexia Sarcopenia Muscle 2019, 10(6), 1266-1275. https://doi.org/10.1002/jcsm.12481

20. Sáez de Asteasu, M.L.; Martínez-Velilla, N.; Zambom-Ferraresi, F.; Ramírez-Vélez, R.; García-Hermoso, A.; Cadore, E.L.; CasasHerrero, Á.; Galbete, A.; Izquierdo, M. Changes in muscle power after usual care or early structured exercise intervention in acutely hospitalized older adults. J. Cachexia Sarcopenia Muscle 2019,11(4), 997-1006. https://doi.org/10.1002/jcsm.12564

21. Sáez de Asteasu, M.L.; Martínez-Velilla, N.; Zambom-Ferraresi, F.; Casas-Herrero, Á.; Millor, N.; Izquierdo, M. Quantifying physical functional trajectory in hospitalized older adults using body worn inertial sensors. J. Biomech. 2019, 92, 105-111. https://doi.org/10.1016/j.jbiomech.2019.05.038

22. Sáez de Asteasu, M.L.; Martínez-Velilla, N.; Zambom-Ferraresi, F.; Casas-Herrero, Á.; Lucía, A.; Galbete, A.; Izquierdo, M. Physical Exercise Improves Function in Acutely Hospitalized Older Patients: Secondary Analysis of a Randomized Clinical Trial. J. Am. Med. Dir. Assoc. 2019, 20(7), 866-873. https://doi.org/10.1016/j.jamda.2019.04.001

23. Sáez de Asteasu, M.L.; Martínez-Velilla, N.; Zambom-Ferraresi, F.; Ramirez-Vélez, R.; Izquierdo, M. Role of muscle power output as a mediator between gait variability and gait velocity in hospitalized older adults. Exp. Gerontol. 2019, $124,110631$. https://doi.org/10.1016/j.exger.2019.110631

24. Martínez-Velilla, N.; Valenzuela, P.L.; Zambom-Ferraresi, F.; Sáez de Asteasu, M.L.; Ramírez-Vélez, R.; García-Hermoso, A.; Lucia, A.; Izquierdo, M. Tailored exercise is safe and beneficial for acutely hospitalised older adults with COPD. Eur. Respir. J. 2020, 56(6), 2001048. https://doi.org/10.1183/13993003.01048-2020

25. Sáez de Asteasu, M.L.; Martínez-Velilla, N.; Zambom-Ferraresi, F.; Ramírez-Vélez, R.; García-Hermoso, A; Izquierdo, M. Cognitive Function Improvements Mediate Exercise Intervention Effects on Physical Performance in Acutely Hospitalized Older Adults. J. Am. Med. Dir. Assoc. 2020, S1525-8610(20)30731-3. Advance online publication. https://doi.org/10.1016/j.jamda.2020.08.024

26. Ramírez-Vélez, R.; García-Hermoso, A.; Martínez-Velilla, N.; Zambom-Ferraresi, F.; Sáez de Asteasu, M.L.; Recarey, A.E.; Izquierdo, M. Effects of Exercise Interventions on Inflammatory Parameters in Acutely Hospitalized Older Patients: A Systematic Review and Meta-Analysis of Randomized Controlled Trials. J. Clin. Med. 2021, 10(2), 290. https://doi.org/10.3390/jcm10020290

27. Sáez de Asteasu, M.L.; Martínez-Velilla, N.; Zambom-Ferraresi, F.; Ramírez-Vélez, R.; García-Hermoso, A., Cadore, E.L.; Izquierdo, M. Exercise Effects on Brain and Muscle Function in Acutely Hospitalized Older Patients Assessed by Functional Near-Infrared Spectroscopy. J. Am. Med. Dir. Assoc. 2021, S1525-8610(20)31094-X. https://doi.org/10.1016/j.jamda.2020.12.027

28. Ramírez-Vélez, R.; Sáez de Asteasu, M.L.; Martínez-Velilla, N.; Zambom-Ferraresi, F.; García-Hermoso, A.; Izquierdo, M. Handgrip Strength as a Complementary Test for Mobility Limitations Assessment in Acutely Hospitalized Oldest Old. Rejuvenation Res. 2021, 10.1089/rej.2020.2344. https://doi.org/10.1089/rej.2020.2344

29. Martínez-Velilla, N.; Valenzuela, P.L.; Sáez de Asteasu, M.L.; Zambom-Ferraresi, F.; Ramírez-Vélez, R.; García-Hermoso, A.; Librero-López, J.; Gorricho, J.; Pérez, F. E.; Lucia, A.; Izquierdo, M. Effects of a Tailored Exercise Intervention in Acutely Hospitalized Oldest Old Diabetic Adults: An Ancillary Analysis. J. Clin. Endocrinol. Metab. 2021, 106(2), e899-e906. https://doi.org/10.1210/clinem/dgaa809

30. Martínez-Velilla, N.; Sáez de Asteasu, M.L.; Ramírez-Vélez, R.; Zambom-Ferraresi, F.; García-Hermoso, A.; Izquierdo, M. Recovery of the decline in activities of daily living after hospitalization through an individualized exercise programme: Secondary Analysis of a Randomized Clinical Trial. J. Gerontol. 2021. https://doi.org/10.1093/gerona/glab032

31. Martínez Velilla, N.; Ramírez-Vélez, R.; Sáez de Asteasu, M.L.; Zambom-Ferraresi, F.; Garcia Hermoso, A.; Marín Epelde, I.; Izquierdo, M. Red Cell Distribution Width (RDW) Trajectory During a Multicomponent Exercise in Hospitalized Older Adults: A Secondary Analysis of a Randomized Clinical Trial. Rejuvenation Res. 2021, 10.1089/rej.2020.2405. https://doi.org/10.1089/rej.2020.2405

32. French, D.P.; Olander, E.K.; Chisholm, A.; Mc Sharry, J. Which behaviour change techniques are most effective at increasing older adults' self-efficacy and physical activity behaviour? A systematic review. Ann.Behav. Med. 2014, 48(2), 225-234. https://doi.org/10.1007/s12160-014-9593-z

33. Lachman, M.E.; Lipsitz, L.; Lubben, J.; Castaneda-Sceppa, C.; Jette, A.M. When Adults Don't Exercise: Behavioral Strategies to Increase Physical Activity in Sedentary Middle-Aged and Older Adults. Innov. Aging 2018, (2)1, https://doi.org/10.1093/geroni/igy007

34. Chase, J.A. Physical activity interventions among older adults: a literature review. Res. Theory Nurs. Pract. 2013, 27(1), 53-80. https://doi.org/10.1891/1541-6577.27.1.53 
35. Fiatarone, M.A.; O'Neill, E.F.; Ryan, N.D.; Clements, K.M.; Solares, G.R.; Nelson, M.E.; Roberts, S.B.; Kehayias, J.J.; Lipsitz, L.A.; Evans, W.J. Exercise training and nutritional supplementation for physical frailty in very elderly people. N. Engl. J. Med. 1994, 330(25), 1769-1775. https://doi.org/10.1056/NEJM199406233302501

36. Woo, J. Nutrition and Frailty. J. Nutr. Health Ageing 2018, 22, 1025-1027 http://doi.org/10.1007/s12603-018-1120-7

37. Zak, M.; Swine, C.; Grodzicki, T. Combined effects of functionally-oriented exercise regimens and nutritional supplementation on both the institutionalised and free-living frail elderly (double-blind, randomised clinical trial). BMC Public Health $2009,9,39$. https://doi.org/10.1186/1471-2458-9-39

38. Nilsson, M.I.; Mikhail, A.; Lan, L.; Di Carlo, A.; Hamilton, B.; Barnard, K.; Hettinga, B.P.; Hatcher, E.; Tarnopolsky, M.G.; Nederveen, J.P.; Bujak, A.L.; May, L.; Tarnopolsky, M.A. A Five-Ingredient Nutritional Supplement and Home-Based Resistance Exercise Improve Lean Mass and Strength in Free-Living Elderly. Nutrients 2020, 12(8), 2391. https://doi.org/10.3390/nu12082391

39. Zhou, X.; Perez-Cueto, F.; Santos, Q.D.; Monteleone, E.; Giboreau, A.; Appleton, K.M.; Bjørner, T.; Bredie, W.; Hartwell, H. A Systematic Review of Behavioural Interventions Promoting Healthy Eating among Older People. Nutrients 2018, $10(2), 128$. https://doi.org/10.3390/nu10020128

40. Krishna, M.; Jauhari, A.; Lepping, P.; Turner, J.; Crossley, D.; Krishnamoorthy, A. Is group psychotherapy effective in older adults with depression? A systematic review. Int. J. Geriatr. Psychiatry 2011, 26(4), 331-340. https://doi.org/10.1002/gps.2546

41. Coll-Planas, L.; Nyqvist, F.; Puig, T.; Urrútia, G.; Solà, I.; Monteserín, R. Social capital interventions targeting older people and their impact on health: a systematic review. J. Epidemiol. Community Health 2017, 71(7), 663-672. https://doi.org/10.1136/jech2016-208131

42. Duncan, E.; O'Cathain, A.; Rousseau, N.; Croot, L.; Sworn, K.; Turner, K.M.; Yardley, L.; Hoddinott, P. Guidance for reporting intervention development studies in health research (GUIDED): an evidence-based consensus study. BMJ Open 2020, 10(4), e033516. https://doi.org/10.1136/bmjopen-2019-033516.

43. APTITUDE. Un réseau transpyrénéen au service des personnes âgées. Available at http://www.aptitude-net.com (accessed on 18 March 2021).

44. Bases conceptuals i model d'atenció per a les persones fràgils, amb cronicitat complexa (PCC) o avançada (MACA). Department of Health, Government of Catalonia. Available at: https://salutweb.gencat.cat/web/.content/_ambits-actuacio/Linies-dactuacio/Estrategies-de-salut/Cronicitat/Documentacio-cronicitat/arxius/Model-de-Bases-de-Cronicitat.pdf (accessed on $18 \mathrm{March}$ 2021).

45. O'Cathain, A.; Croot, L.; Duncan, E.; Rousseau, N.; Sworn, K.; Turner, K.M.; Yardley, L.; Hoddinott, P. Guidance on how to develop complex interventions to improve health and healthcare. BMJ Open 2019, 9(8), e029954. https://doi.org/10.1136/bmjopen-2019-029954.

46. Izquierdo M.; Casas-Herrero A.; Zambom-Ferraresi F. et al. Multicomponent physical exercise program VIVIFRAIL. Available at: http://vivifrail.com/resources/ 2017 (accessed on 08 March 2021).

47. Coll-Planas, L.; Blancafort, S.; Rojano, X.; Roqué, M.; Monteserín, R. Promoting self-management, health literacy and social capital to reduce health inequalities in older adults living in urban disadvantaged areas: protocol of the randomised controlled trial AEQUALIS. BMC Public Health 2018, 18(1), 345. https://doi.org/10.1186/s12889-018-5219-x.

48. Hoffmann, T.C.; Glasziou, P.P.; Boutron, I.; Milne, R.; Perera, R.; Moher, D.; Altman, D.G.; Barbour, V.; Macdonald, H.; Johnston, M.; Lamb, S.E.; Dixon-Woods, M.; McCulloch, P.; Wyatt, J.C.; Chan, A.W.; Michie, S. Better reporting of interventions: template for intervention description and replication (TIDieR) checklist and guide. Br. Med. J. 2014,348, g1687. https://doi.org/10.1136/bmj.g1687.

49. de Moraes, M.B.; Avgerinou, C.; Fukushima, F.B.; Vidal, E. Nutritional interventions for the management of frailty in older adults: systematic review and meta-analysis of randomized clinical trials. Nutr. Rev. 2020. https://doi.org/10.1093/nutrit/nuaa101

50. Blancafort Alias, S.; Monteserín Nadal, R.; Moral, I.; Roqué Fígols, M.; Rojano Luque, X.; Coll-Planas, L. Promoting social capital, self-management and health literacy in older adults through a group-based intervention delivered in low-income urban areas: results of the randomized trial AEQUALIS. BMC Public Health 2021, 21(1), 84. https://doi.org/10.1186/s12889-020-10094-9

51. Chiu, H.L.; Chu, H.; Tsai, J.C.; Liu, D.; Chen, Y.R.; Yang, H.L.; Chou, K.R. The effect of cognitive-based training for the healthy older people: A meta-analysis of randomized controlled trials. PloS One 2017, 12(5), e0176742. https://doi.org/10.1371/journal.pone.0176742

52. George, J.; Elliott, R.A.; Stewart, D.C. A systematic review of interventions to improve medication taking in elderly patients prescribed multiple medications. Drugs Aging 2008, 25(4), 307-324. https://doi.org/10.2165/00002512-200825040-00004

53. Boulos, C.; Salameh, P.; Barberger-Gateau, P. Social isolation and risk for malnutrition among older people. Geriatr. Gerontol. Int. 2017, 17(2), 286-294. https://doi.org/10.1111/ggi.12711

54. Epton, T.; Currie, S.; Armitage, C.J. Unique effects of setting goals on behavior change: Systematic review and meta-analysis. J. Consult. Clin. Psychol. 2017, 85(12), 1182-1198. https://doi.org/10.1037/ccp0000260 
55. Shilts, M.K.; Horowitz, M.; Townsend, M.S. Goal setting as a strategy for dietary and physical activity behavior change: a review of the literature. Am. J. Health Promot. 2004, 19(2), 81-93. https://doi.org/10.4278/0890-1171-19.2.81

56. Vermunt, N.; Harmsen, M.; Westert, G.P.; Olde Rikkert, M.; Faber, M.J. Collaborative goal setting with elderly patients with chronic disease or multimorbidity: a systematic review. BMC Geriatr. 2017, 17(1), 167. https://doi.org/10.1186/s12877-017-0534-0

57. Sagar-Ouriaghli, I.; Godfrey, E.; Graham, S.; Brown, J. Improving Mental Health Help-Seeking Behaviours for Male Students: A Framework for Developing a Complex Intervention. Int. J. Environ. Res. Public Health 2020, 17(14), 4965. https://doi.org/10.3390/ijerph17144965

58. Moon, Z.; Moss-Morris, R.; Hunter, M.S.; Hughes, L.D. Development of a self-management intervention to improve tamoxifen adherence in breast cancer survivors using an Intervention Mapping framework. Support. Care Cancer 2020 https://doi.org/10.1007/s00520-020-05850-x

59. Surgey, A.; Disbeschl, S.; Lewis, R.; Hiscock, J.; Nafees, S.; Law, J.; Roberts, J.L.; Hendry, A.; Hoare, Z.; Goulden, N.; Stanciu M.A.; Carson-Stevens, A.; Smits, S.; Brain, K.; Edwards, R.T.; Williams, N.; Neal, R.D.; Wilkinson, C. ThinkCancer! The multimethod development of a complex behavior change intervention to improve the early diagnosis of cancer in primary care. medRxiv 2020, 2020.11.20.20235614. https://doi.org/10.1101/2020.11.20.20235614

60. Walsh, K.A.; Byrne, S.; Mc Sharry, J.; Browne, J.; Irving, K.; Hurley, E.; Rochford-Brennan, H.; Geoghegan, C.; Presseau, J.; Timmons, S. Developing a complex intervention targeting antipsychotic prescribing to nursing home residents with dementia. HRB Open Res. 2021, 4:23. https://doi.org/10.12688/hrbopenres.13228.1

61. Carswell, C. Development and feasibility of an arts-based intervention for patients with end-stage kidney disease whilst receiving haemodialysis. PhD Nursery and Midwifery, Queen's University, Belfast, 17 september 2020. 